\title{
Sexual Dysfunction in Inflammatory Bowel Disease: What the Specialist Should Know and Ask
}

Edith Perez de Arce ${ }^{\prime}$

Rodrigo Quera ${ }^{2}$

Jaqueline Ribeiro Barros (D) ${ }^{3}$

Ligia Yukie Sassaki (D) ${ }^{3}$

'Department of Gastroenterology, Hospital Clínico Universidad de Chile, Santiago, Chile; ${ }^{2}$ Inflammatory Bowel Disease Program, Gastroenterology, Medicine Department, Clinica Universidad de los Andes, Santiago, Chile; ${ }^{3}$ Department of Internal Medicine, São Paulo State University (Unesp), Medical School, Botucatu, Brazil
Correspondence: Ligia Yukie Sassaki Department of Internal Medicine, São Paulo State University (Unesp), Medical School, Av. Prof. Mário Rubens Guimarães Montenegro, s/n. Bairro: Rubiao Junior, Botucatu, São Paulo, |86|8687, Brazil

Tel $+55 \mid 43880$ I I7I

$\mathrm{Fax}+551438801667$

Email ligiasassaki@gmail.com

\begin{abstract}
Inflammatory bowel disease (IBD) is a chronic condition that globally affects the health of people who suffer from it, deteriorating their quality of life (QoL). An aspect rarely explored by healthcare providers is the influence of the disease on the sexual functioning of individuals. This discretion is mainly due to an unconscious resistance when asking our patients about their sexual functioning because of a lack of knowledge and skills to tackle this topic or disinterest on the part of professionals, and fear or shame on the part of patients. Sexual function is a constant concern in IBD patients that has been reflected in several studies, especially if we consider that the prevalence of sexual dysfunction (SD) in IBD is higher than that reported in the general population. The etiology of SD in patients with IBD remains unclear but is likely to be multifactorial, where biological, psychosocial, and disease-specific factors are involved. Currently, there are no formal recommendations in the IBD clinical guidelines on how to manage SD in these patients. The use of validated clinical scales could improve the detection of SD and allow the treatment of the underlying causes in order to improve the QoL of patients with IBD. This review aims to illustrate the different aspects involved in SD in IBD patients and the importance of the participation of a multidisciplinary team in the early detection and treatment of SD at different stages of the disease.
\end{abstract}

Keywords: sexual dysfunction, ulcerative colitis, Crohn's disease, inflammatory bowel disease

\section{Introduction}

Inflammatory bowel disease (IBD) is a group of chronic diseases that affects the digestive tract and is characterized by periods of clinical activity and remission. Its main representatives are ulcerative colitis (UC) and Crohn's disease (CD). Although its etiopathogenesis is still unknown, genetic, microbiota, immunological, and environmental factors are important in the development and evolution of these diseases. ${ }^{1,2}$ More than $50 \%$ of patients are diagnosed with IBD before the 35 years, ${ }^{3}$ a stage in life in which body image and interpersonal relationships acquire a greater relevance. IBD, like other chronic diseases, alters the quality of life (QoL) of individuals who suffer from it due to their symptoms (intestinal and extraintestinal symptoms), the need for hospitalization and surgery, the deterioration of body image secondary to malnutrition, psychological disorders associated with the disease, chronic pharmacological treatment, and economic costs, among other factors. ${ }^{4}$ All these factors interfere with the multidimensional and integral development of 
the individual, which considers the sexual functioning of patients with IBD. This part is rarely evaluated during the evolution of the disease, but it is a priority within the concerns of IBD patients. ${ }^{5,6}$ This review aims to assess the available scientific evidence regarding sexual dysfunction (SD) in IBD patients, including the SD assessment tools and the clinical and psychological factors associated with SD.

\section{Materials and Methods Database Searches}

An electronic search of the literature was performed using MEDLINE (PubMed), Google Scholar, and ResearchGate databases from January 1978 to September 2020. Only articles published in English and Spanish languages were included. Keywords used in the search were inflammatory bowel disease, Crohn's disease, ulcerative colitis, sexual dysfunction, sexual health, erectile dysfunction, quality of life, ileal pouch-anal anastomosis, scale, index and questionnaire. Studies on reproduction and fertility in IBD were excluded. Both retrospective and prospective studies and cross-sectional designs were included, in addition to reviews and systematic reviews. Finally, 70 articles were analyzed for this review.

\section{Definitions of Sexuality and Sexual Dysfunction}

According to the World Health Organization, sexuality is defined as

... a central aspect of being human throughout life. It encompasses sex, gender identities and roles, eroticism, pleasure, intimacy, reproduction, and sexual orientation. ${ }^{7}$

The human sexual response is the result of complex interactions between biological and psychological factors that can vary between cultures, individuals, and even within the same individual.

SD is defined as a sexual problem that is persistent or recurring and causes marked personal distress or interpersonal difficulty. ${ }^{8}$ It should not be better explained by a medical or psychiatric condition (ie, anxiety and depression) or exclusively due to the direct physiological effects of a substance or medication. ${ }^{8} \mathrm{SD}$ can occur in any of the three phases of sexual response: desire, arousal, and orgasm. SD in women includes a lack of sexual desire, impaired arousal, inability to orgasm, pain with sexual activity, or a combination of these problems. ${ }^{8,9}$ The most recognized disorders in men are erectile dysfunction, decreased libido, and abnormal ejaculation. ${ }^{8}$

\section{Overview of Sexual Dysfunction in IBD}

The first report of SD in patients with IBD was published in 1978 in patients with CD with more than one year of disease progression. Of the 52 married patients, 28 reported that sexual intercourse was less frequent, and another 12 ceased sexual contact completely. ${ }^{10}$ Subsequently, in 1996 a study that included 50 women with CD revealed that $24 \%$ of them had either infrequent or no sexual intercourse compared with $4 \%$ of controls, mainly due to abdominal pain (24\%), diarrhea (20\%), and fear of fecal incontinence (14\%), in addition to registering a higher frequency of dyspareunia and vaginal candidiasis. ${ }^{11}$ Since then, several studies have confirmed that SD rates are higher in patients with IBD than in the general population, ${ }^{12}$ and affect up to $60 \%$ of women and $15 \%$ of men with IBD compared with $30 \%$ in women and $5 \%$ in men in the general population. ${ }^{12-14}$ Data obtained from a recent meta-analysis confirmed these findings, with a relative risk (RR) of 1.41 and 1.76 for SD in men and women with IBD, respectively. ${ }^{15}$

\section{Sexual Dysfunction Assessment Tools}

The tools to evaluate SD vary; however, most are nonspecific for IBD patients, especially if we consider variables of the disease such as perianal disease in $C D$, surgeries, or the presence of an ostomy, among others, which can undoubtedly influence the results. The scales directed to the evaluation of the QoL (IBD-Q) or other aspects of IBD contain some items referring to general sexual function in this population, touching the subject tangentially. ${ }^{16}$ For this reason, most of the authors who have evaluated SD in IBD have used the Female Sexual Function Index (FSFI) ${ }^{17}$ and the International Index of Erectile Function (IIEF) ${ }^{18}$ as a reference in their studies. $^{12,13,19-22}$ The FSFI is a multidimensional selfreport scale for women that consists of 19 items and evaluates six domains: desire, subjective arousal, orgasm, lubrication, and pain within the previous 4 weeks. The score obtained for each domain is multiplied by a factor, whose sum of the value from each domain gives the total score on the scale, with a maximum of 36 points. Higher scores reflect better sexual functioning ${ }^{17}$ (Table 1). According to the authors, a total score of 26.55 can differentiate women with and without SD. ${ }^{23}$ The IIEF is an index whose original version has 15 items with five 
Table I Summary Table of Selected Scales and Questionnaires for Sexual Dysfunction

\begin{tabular}{|c|c|c|c|c|c|}
\hline Questionnaire & $\begin{array}{c}\text { Target } \\
\text { Population }\end{array}$ & Items & Domains/Topics & Cutoff Scores for SD & Reference \\
\hline \multicolumn{6}{|l|}{ General Scales } \\
\hline $\begin{array}{l}\text { Female Sexual } \\
\text { Function Index } \\
\text { (FSFI) } \\
\text { Level of Evidence } \\
\text { I-A }\end{array}$ & $\begin{array}{l}\text { Women- } \\
\text { heterosexual } \\
\text { and homosexual }\end{array}$ & $\begin{array}{l}19 \text { (original } \\
\text { version) } \\
6 \\
\text { (abbreviated } \\
\text { version) }\end{array}$ & $\begin{array}{l}\text { I. Desire } \\
\text { 2. Arousal } \\
\text { 3. Lubrication } \\
\text { 4. Orgasm, } \\
\text { 5. Satisfaction } \\
\text { 6. Pain }\end{array}$ & $\begin{array}{l}\text { FSFI total score } \leq 26 \text { : SD } \\
\text { Lower score indicates } \\
\text { higher severity of sexual } \\
\text { dysfunction }\end{array}$ & $\begin{array}{l}\text { Rosen et al } \\
2000^{17} \\
\text { Wiegel } \\
\text { et al } 2005^{23}\end{array}$ \\
\hline $\begin{array}{l}\text { International Index } \\
\text { of Erectile Function } \\
\text { (IIEF) } \\
\text { Level of Evidence } \\
\text { I-A }\end{array}$ & $\begin{array}{l}\text { Men from } \\
\text { community and } \\
\text { medical } \\
\text { populations }\end{array}$ & $\begin{array}{l}\text { I5 (original } \\
\text { version) } \\
5 \\
\text { (abbreviated } \\
\text { version) }\end{array}$ & $\begin{array}{l}\text { I. Erectile function, } \\
\text { 2. Orgasmic function } \\
\text { 3. Sexual desire } \\
\text { 4. Intercourse satisfaction } \\
\text { 5. Overall satisfaction }\end{array}$ & $\begin{array}{l}\text { I. Erectile function (score } \\
\text { range 0-30) } \\
\text { - 6-10: severe ED } \\
\text { - II-16: moderate ED } \\
\text { 17-25: mild ED } \\
\text { - 26-30: non ED } \\
\text { I. Orgasmic function (range } \\
0-10 \text { ) } \\
\text { 2. Sexual desire (range } \\
0-10 \text { ) } \\
\text { 3. Satisfaction in sexual } \\
\text { intercourse (range } 0-15 \text { ) } \\
\text { 4. General satisfaction } \\
\text { (range 0-10) } \\
\text { Lower score indicates } \\
\text { higher severity of sexual } \\
\text { dysfunction }\end{array}$ & $\begin{array}{l}\text { Rosen et al } \\
1997^{18} \\
\text { Rosen et al } \\
1999^{24}\end{array}$ \\
\hline \multicolumn{6}{|l|}{ Specific Scales } \\
\hline $\begin{array}{l}\text { IBD-specific Female } \\
\text { Sexual Dysfunction } \\
\text { Scale (IBD-FSDS) }\end{array}$ & $\begin{array}{l}\text { Women with } \\
\text { IBD }\end{array}$ & 15 & $\begin{array}{l}\text { How CD or UC affect sexual functioning: } \\
\text { - sexual distress } \\
\text { - preventing sexual activity or sexual } \\
\text { - relationships } \\
\text { - delayed sexual activity } \\
\text { - causing problems during sex } \\
\text { - awareness of disease during intercourse } \\
\text { - worried about or symptoms during inter- } \\
\text { - course (abdominal or pelvic or rectal pain) } \\
\text { - fesire or arousal } \\
\text { - negative feelings toward sexual activity } \\
\text { - nexual satisfaction }\end{array}$ & $\begin{array}{l}\text { - Maximal score: } 92 \\
\text { vach item was scored indi- } \\
\text { on a Likert-type scale } \\
\text { Higher scores indicate } \\
\text { greater severity of sexual } \\
\text { dysfunction }\end{array}$ & $\begin{array}{l}\text { De Silva } \\
\text { et al } 2018^{30}\end{array}$ \\
\hline $\begin{array}{l}\text { IBD-Male Sexual } \\
\text { Dysfunction Scale } \\
\text { (IBD-MSDS) }\end{array}$ & Men with IBD & 10 & $\begin{array}{l}\text { How CD or UC affect sexual functioning: } \\
\text { - desire } \\
\text { - participating in sexual activity } \\
\text { - preventing having sex } \\
\text { - causing problems during sex } \\
\text { - feeling guilty about sex } \\
\text { - fatigue or lack of energy } \\
\text { - other symptoms (abdominal or pelvic pain, } \\
\text { bowel movements, anal bleeding or dis- } \\
\text { charge, anal pain, discomfort or irritation) }\end{array}$ & $\begin{array}{l}\text { - Maximal score: } 40 \\
\text { - Each individual item was } \\
\text { scored from } 0 \text { to } 4 \text { points } \\
\text { on a Likert-type scale } \\
\text { Higher score indicates } \\
\text { greater severity of sexual } \\
\text { dysfunction }\end{array}$ & $\begin{array}{l}\text { O'Toole } \\
\text { et al } 2018^{29}\end{array}$ \\
\hline
\end{tabular}

Abbreviations: SD, sexual dysfunction; ED, erectile dysfunction; IBD, inflammatory bowel disease.

categories: erectile function, orgasm, sexual desire, sexual satisfaction, and general satisfaction. Higher scores reflect better sexual functioning ${ }^{18}$ (Table 1). The abbreviated version contains five questions (IIEF-5) and has been validated for clinical use, ${ }^{24}$ and evaluates the SD within the previous 6 months: a cutoff score of 21 (range of score 5-25) better discriminates the presence or absence of erectile dysfunction (ED). The Patient Reported Outcome Measurement Information System (PROMIS ${ }^{\circledR}$ ) Sexual Function is a sexual dysfunction scale previously 
developed in cancer patients. It is currently validated in the general population with and without chronic disease, ${ }^{25}$ being used by some authors in patients with IBD. ${ }^{26,27}$

Other scales include the Brief Index of Sexual Functioning for Women (BISF-W), Female Sexual Distress Scale (FSDS), and Arizona Sexual Experiences Scale (ASEX) ${ }^{16,28}$ Recently, O'Toole et al developed a new specific scale for sexual functioning in men with IBD, which consists of 10 items that consider the patient's symptoms (IBD-Male Sexual Dysfunction Scale or IBDMSDS); however, its use is not yet widespread. ${ }^{29} \mathrm{~A}$ higher total score indicates a greater SD (maximum score: 40) (Table 1). Also, from the same research group, De Silva et $\mathrm{al}^{30}$ designed a new scale for SD in women with IBD: IBD-specific Female Sexual Dysfunction Scale (IBDFSDS), which includes 15 items. Similar to the O'Toole et $\mathrm{al}^{29}$ scale, this scale assesses how IBD symptoms interfere with sexual function in women ${ }^{30}$ (Table 1).

\section{Characteristics of Sexual Dysfunction in Men and Women with IBD}

ED rates of up to $40 \%$ have been reported in men with IBD compared to $15 \%$ in the general population of the same age. ${ }^{12,14,31}$ However, a recent study that included 69 men newly diagnosed with IBD, 39\% had a global SD, and $94 \%$ suffered from ED, using the IIEF. ${ }^{32}$ A previous study found that $44 \%$ of men felt severely sexually compromised due to IBD, mainly in those with active disease. ${ }^{33}$ Also, in men with IBD, a decrease in sexual desire was more frequent than in the general population. ${ }^{12}$ In accordance with this point, Marín et al showed that a third of men considered that sexual desire and satisfaction worsened after the diagnosis of IBD. Despite the finding of lower SD scores in all IIEF domains, only erectile dysfunction, and sexual desire domains were significantly affected $(\mathrm{p}=$ 0.044 and $p=0.031$, respectively). ${ }^{13}$

Regarding the female population, a prospective cohort of 130 women with newly diagnosed IBD found a $97 \%$ of SD according to FSFI, with no difference between CD and $\mathrm{UC}(\mathrm{p}=0.22)$, and there were no significant changes in FSFI score or individual domain scores throughout the 2-year study period despite reaching clinical remission. ${ }^{34}$ Older age, non-single marital status, a score on the Short Form-36 Health Survey (SF-36) with a lower physical component, and the use of biological therapy were independent risk factors for SD in women. ${ }^{34}$ In 2010, Muller et al reported that women with IBD had a negative impact on their body image (Odds Ratio 3.24), libido (Odds Ratio 3.57), and frequency of sexual activity (Odds Ratio 3.89), regardless of disease duration, age at onset, and type of surgery. ${ }^{35}$

Despite the evidence of the decreased frequency of sexual activity in patients with IBD, some authors have reported that the rate of sexual activity in patients with IBD would be similar to that of healthy individuals, but with a lower satisfaction rate. ${ }^{12,27}$ Similar to the general population, older patients ${ }^{13,27,36}$ and the presence of depression and anxiety could play a role in SD in patients with IBD, showing lower levels of sexual interest and satisfaction, and lower QoL for IBD patients. ${ }^{27}$ However, in relation to age, a recent meta-analysis that included 8 studies found that relatively younger IBD patients (men $<50$ years, women $<40$ years) had a higher risk of SD than those of older age. ${ }^{15}$ The authors attributed this finding to the age of IBD diagnosis, which occurs regularly between 15 and 35 years of age, impacting early and negatively the sexual development of individuals in the context of chronic disease. Other factors that may be involved in $\mathrm{SD}$ in IBD patients are discussed and summarized in Figure 1. Table 2 summarizes the main studies on SD in IBD.

\section{Subtype of IBD}

Several reasons could explain the differences in SD rates between patients with $\mathrm{CD}$ and $\mathrm{UC}$; however, the results of the studies are not conclusive. The distinctive characteristics of each disease (spectrum of symptoms, the extent of UC, segments involved in $\mathrm{CD}$, need and types of surgeries, and therapies used at the time of the study, among others) could influence SD rates on each; however, patient selection among the studies is highly heterogeneous. In the study published by Muller et al, no differences were found in SD rates between patients with $\mathrm{CD}$ and $\mathrm{UC}$; however, the study did not detail the segments affected by $\mathrm{CD}$, the extent of UC involvement, or the presence of clinical disease activity. ${ }^{35}$ In another study, Shmidt et al found no difference between the FSFI in women with $\mathrm{UC}$ and $\mathrm{CD}$; however, only 3 of 60 women with CD had anal fistulas, and all of them showed an FSFI 6 points lower than the rest of the patients $(p=0.043) .{ }^{34}$ Consistent with these findings, Moody et al found that women with perianal fistula had higher rates of dyspareunia than those with other gastrointestinal tract involvement. ${ }^{11}$ Furthermore, a recent crosssectional study that included a population-based cohort of Danish women showed that those with CD reported more 
Factors involved in development of Sexual Dysfunction in IBD

\begin{tabular}{|c|c|c|}
\hline & Biological Factors & $\begin{array}{l}\text { - Older age }{ }^{13,27,36} \\
\text { - Female }>\text { Male } 4,6,13,21,35,53 \\
\text { - Other medical conditions: diabetes }{ }^{13}, \text { hypogonadism }{ }^{76}\end{array}$ \\
\hline & Related IBD Factors & $\begin{array}{l}C D>U C^{37} \\
\text { Active perianal Crohn disease }{ }^{11,34} \\
\text { Disease activity? }{ }^{26,36} \text { duration of disease? }{ }^{29,38}\end{array}$ \\
\hline & Drugs & $\begin{array}{l}\text { IBD: corticoids }{ }^{13,36} \text {, methotrexate }{ }^{71,72^{*}} \text {, sulfasalazine }{ }^{73^{*}} \text {, biologics }{ }^{34^{* *}} \\
\text { Non IBD: psychotropics }{ }^{74} \text {, opioids }{ }^{75}\end{array}$ \\
\hline & Surgical Factors & $\begin{array}{l}\text { - Other abdomino-pelvic surgeries > IPAA } 56 \\
\text { - Presence ostomy }{ }^{20,35} \\
\text { - Perianal surgery? }{ }^{20}\end{array}$ \\
\hline & Psychological Factors & - Anxiety and/or depression $13,14,29,33,35,52$ \\
\hline & Social Factors & $\begin{array}{l}\text { - Prior sexual experiences }{ }^{28} \\
\text { - Social and cultural context }{ }^{36}\end{array}$ \\
\hline
\end{tabular}

Figure I Factors involved in development of sexual dysfunction in IBD. *Only case report. **This finding could be due to unmeasured disease activity.

frequent dyspareunia (Odds ratio 1.71) and difficulty in achieving orgasm (Odds ratio 1.53) than women with UC or without IBD; however, the extent of CD in these patients was not described. ${ }^{37}$

\section{Disease Duration}

Regarding disease duration and $\mathrm{SD}$, the results are controversial. Muller et al reported that patients of both genders with a long duration of the disease ( $>$ three years) were 2.59 times more likely to have decreased libido $(\mathrm{p}=$ 0.053). ${ }^{35}$ However, a previous study showed that a disease duration $>10$ years was not a determinant of low sexual function in women with IBD, unlike the presence of depression. $^{36}$ On the other hand, O'Toole et al reported a $94 \%$ of $\mathrm{SD}$ in men with IBD, which is a significantly higher percentage than that published by other authors. In this study, the patients had an average IBD duration of 14 years, and almost $50 \%$ of patients used biological therapy, which implies greater severity and cumulative damage over time, which could explain the high prevalence of SD. ${ }^{29}$ Unlike men, in women with SD, psychological factors appear early in the course of the disease and remain constant throughout the disease, persisting despite the improvement in clinical activity. ${ }^{34}$ More prospective cohort studies are needed to clarify the role of disease duration in SD in patients with IBD.

\section{Disease Activity}

Clinical manifestations of IBD, such as abdominal pain, diarrhea, rectal bleeding, and other rectal symptoms, and the need for surgery, could impair the sexual function of IBD patients. ${ }^{38,39}$ However, the relationship between disease activity and SD is not entirely clear. Assessment of disease activity across studies is heterogeneous and based primarily on clinical scales. One study reported an association between SD and clinical disease activity (Crohn's Disease Activity Index [CDAI] for CD, Colitis Activity Index [CAI] for UC) in men with IBD. ${ }^{33}$ On the other hand, a study carried out in 168 women, and 119 men with IBD showed that patients with active disease had significantly lower scores on the IIEF-5 and FSFI than patients in remission; however, the association between clinical activity and SD was explained by depression. ${ }^{14}$ Following the same line, Riviere et al, who reported high rates of SD in IBD subjects (54\% SD in women and 43\% ED in men versus $28 \%$ and $13 \%$ in control subjects, respectively), found that these rates were independent of clinical disease activity. ${ }^{12}$ Finally, a significant relationship has been found between the deterioration of body image and the clinical activity of IBD, which could influence sexual functioning. ${ }^{40}$ Discordant results between studies could be explained by the use of clinical scales to establish disease activity; the presence of symptoms is not 
Table 2 Summary of the Main Studies on Sexual Dysfunction in IBD Patients

\begin{tabular}{|c|c|c|c|c|c|c|}
\hline Study & Design Study & Gender & $\begin{array}{l}\text { Specific } \\
\text { Disease }\end{array}$ & Patients & Questionnaire & Outcomes \\
\hline $\begin{array}{l}\text { Moody et al } \\
1992^{11}\end{array}$ & Case control & $\mathrm{F}$ & $C D$ & $50 \mathrm{CD} / 50 \mathrm{HC}$ & $\begin{array}{l}\text { The structured } \\
\text { questionnaire }\end{array}$ & $\begin{array}{l}\text { Infrequent or no intercourse vs } \mathrm{HC} \text { due to } \\
\text { symptoms }\end{array}$ \\
\hline $\begin{array}{l}\text { Timmer et al } \\
2007^{53}\end{array}$ & Case control & $M / F$ & CD/UC & $\begin{array}{l}\text { Women: } 222 \\
\text { IBD//8I } \\
\text { controls } \\
\text { Men: I86 IBD/ } \\
\text { I53 controls }\end{array}$ & $\begin{array}{l}\text { BISF-W } \\
\text { IIEF }\end{array}$ & $\begin{array}{l}\text { Women: total BISS-W score were lower in } \\
\text { IBD vs HC } \\
\text { Men: Total IIEF scores were not different } \\
\text { between IBD vs HC } \\
\text { Both, women and men, depression was the } \\
\text { most important determinant of low sexual } \\
\text { function in IBD }\end{array}$ \\
\hline $\begin{array}{l}\text { Marin et al } \\
2013^{13}\end{array}$ & Case control & $M / F$ & CD/UC & $\begin{array}{l}\text { Women: } 202 \\
\text { IBD/I } 27 \mathrm{HC} \\
\text { Men: I53 IBD/ } \\
73 \mathrm{HC}\end{array}$ & $\begin{array}{l}\text { FSFI } \\
\text { IIEF }\end{array}$ & $\begin{array}{l}\text { Lower scores in sexual indexes vs HC, but } \\
\text { higher prevalence of SD was only noticed } \\
\text { in women } \\
\text { Main risk factors for low score IIEF: } \\
\text { depression and diabetes }\end{array}$ \\
\hline $\begin{array}{l}\text { Bel et al } \\
2015^{14}\end{array}$ & Case control & $M / F$ & CD/UC & $\begin{array}{l}\text { Women: } 168 \\
\text { Men: } 119\end{array}$ & $\begin{array}{l}\text { FSFI } \\
\text { IIEF }\end{array}$ & $\begin{array}{l}\text { SD in women: } 52 \% \text { vs } 44 \% \mathrm{HC} \text {. } \\
\text { SD in men: } 25 \% \text { in both, IBD and } \mathrm{HC} \text {, but } \\
\text { higher SD with disease activity }\end{array}$ \\
\hline $\begin{array}{l}\text { Rivière et al } \\
2017^{12}\end{array}$ & $\begin{array}{l}\text { Cross-sectional } \\
\text { (comparing IBD, } \\
\mathrm{HC} \text { and IBS) }\end{array}$ & $M / F$ & CD/UC & $\begin{array}{l}\text { Women: } 192 \\
\text { IBD/54 HC/54 } \\
\text { IBS } \\
\text { Men: } 166 \text { IBD/ } \\
56 \mathrm{HC} / 53 \text { IBS }\end{array}$ & $\begin{array}{l}\text { FSFI } \\
\text { IIEF }\end{array}$ & $\begin{array}{l}\text { SD in women: } 54 \% \text { (rates were significantly } \\
\text { higher than HC) } \\
\text { ED: } 53.6 \%\end{array}$ \\
\hline $\begin{array}{l}\text { Eluri et al } \\
2018^{27}\end{array}$ & Cross-sectional & $M / F$ & CD/UC & $\begin{array}{l}\text { Women: } 1824 \\
\text { Men: } 745\end{array}$ & $\begin{array}{l}\text { PROMIS } \\
\text { SexFS (Sexual } \\
\text { function and } \\
\text { satisfaction) }\end{array}$ & $\begin{array}{l}\text { Low sexual satisfaction in IBD patients vs } \\
\text { general population }\end{array}$ \\
\hline $\begin{array}{l}\text { Schmidt et al } \\
2019^{32}\end{array}$ & $\begin{array}{l}\text { Prospective } \\
\text { cohort }\end{array}$ & $M$ & CD/UC & 82 men & IIEF & $\begin{array}{l}\text { Global SD: } 39 \% \\
\text { ED: } 94 \%\end{array}$ \\
\hline $\begin{array}{l}\text { Schmidt et al } \\
2019^{34}\end{array}$ & $\begin{array}{l}\text { Prospective } \\
\text { cohort }\end{array}$ & $\mathrm{F}$ & CD/UC & I 30 women & FSFI & $\begin{array}{l}\text { SD: } 97 \% \\
\text { DS did not improve over time despite } \\
\text { improvement in disease activity }\end{array}$ \\
\hline $\begin{array}{l}\text { Nohr et al } \\
2020^{37}\end{array}$ & Cross-sectional & $\mathrm{F}$ & CD/UC & $\begin{array}{l}605 \text { IBD women } \\
37,406 \text { non IBD } \\
\text { women }\end{array}$ & $\begin{array}{l}\text { Danish National } \\
\text { Health Survey } \\
\text { (adaptation) }\end{array}$ & $\begin{array}{l}\text { CD patients had more difficulty achieving } \\
\text { orgasm and increased dyspareunia vs non } \\
\text { IBD }\end{array}$ \\
\hline
\end{tabular}

Abbreviations: M, male; F, female; SD, sexual dysfunction; ED, erectile dysfunction; IBD, inflammatory bowel disease; CD, Crohn disease; UC, ulcerative colitis; IBS, irritable bowel disease; HC, health controls; IIEF, International Index for Erectile Function; FSFI, Female Sexual Function Index; PROMIS, Patient Reported Outcome Measurement Information System; Sex SF, sexual function and satisfaction questionnaire.

a reliable indicator of activity, and even these may appear later. $^{41}$ Furthermore, other conditions such as irritable bowel syndrome (IBS), celiac disease, or small intestinal bacterial overgrowth can coexist with IBD, affecting the sexual function of these patients. ${ }^{42,43}$ Riviere et al compared the prevalence of SD among patients with IBD, IBS, and control subjects, and observed high rates of SD in IBS patients $(77.6 \%$ in women and $24.6 \%$ in men, and $55 \%$ of erectile dysfunction in men), which was slightly higher than in IBD, but the difference was not statistically significant. ${ }^{12}$ Fass et al demonstrated a correlation between a higher severity of IBS symptoms and the presence of SD. ${ }^{42}$ Interestingly, a recent study showed that $36 \%$ and $37 \%$ of patients with $\mathrm{CD}$ and $\mathrm{UC}$, respectively, who were 
in deep remission (clinical, endoscopic and histological remission), met the Rome III criteria for IBS, and this IBD/IBS overlap affected clinical activity scores in IBD. ${ }^{44}$ Undoubtedly, IBD activity measured by biomarkers such as fecal calprotectin or C-reactive protein ${ }^{45}$ and the use of endoscopic activity indices could determine the real association between disease activity and SD in IBD patients.

\section{Role of Fatigue in Sexual Dysfunction}

Fatigue is a common symptom in IBD and is present in up to $50 \%$ of patients at diagnosis. ${ }^{46}$ Although its origin is multifactorial, it has been related, among other factors, to the inflammatory activity of the disease. ${ }^{47}$ In addition, fatigue has been reported in up to $40 \%$ of patients in clinical remission based on symptom scales (HarveyBradshaw Index $[\mathrm{HBI}]$ in $\mathrm{CD}$ and $\mathrm{CAI}$ in $\mathrm{UC}){ }^{48}$ A recent study found an inverse relationship between fatigue and clinical and endoscopic remission, showing that deep remission had lower rates of fatigue compared to patients with only clinical remission. ${ }^{49}$ Interestingly, a study by Marín et al in patients with IBD and SD found that fatigue was the main symptom reported by patients as a determining factor in the deterioration of their sexual activity after the diagnosis of IBD $;^{13}$ however, its relationship with disease activity was not determined.

\section{Sexual Dysfunction and Psychiatric Comorbidities in IBD}

$\mathrm{SD}$ is a common symptom in depression, ${ }^{50}$ so this may be a relevant factor of SD in patients with IBD. The prevalence of psychiatric comorbidity in patients with IBD is higher than that in the general population. A systematic review of 13 studies $^{51}$ reported a prevalence of anxiety of $19.1 \%$ in IBD patients compared to $9.6 \%$ in controls; the prevalence of depression was $21.2 \%$ vs $13.4 \%$ in controls, being higher in active IBD in comparison to IBD in remission (anxiety $66.4 \%$ vs $28.2 \%$ and depression $34.7 \%$ vs $19.9 \%$, respectively) and in CD vs UC (anxiety $37 \%$ vs $31 \%$ and depression $24.4 \%$ vs $22 \%$, respectively). Depression has been the most consistent negative predictive factor for SD in most studies ${ }^{13,14,29,33,35,52}$ and could be related, among other factors, to the chronic course of IBD. Similarly, Bel et al found that the univariate association of the clinical activity of IBD on SD could be fully explained by the presence of depression. ${ }^{14}$ Timmer et al showed similar results, where depression (measured by the Hospital Anxiety and Depression Scale - HADS) was the most important factor associated with SD regardless of gender and the presence of IBD. ${ }^{53}$ Finally, in a small series of patients with IBD and depression, six months of treatment with antidepressant medications were associated with improvement in depression, anxiety, QoL, and sexual function. ${ }^{54}$

\section{Sexual Dysfunction and Surgery}

In the pre-biological therapy era, $\mathrm{CD}$ surgery rates reached $80 \%$. Since the initiation of biological therapy, one-year and five-year surgery rates in CD ranged from $10-20 \%$ to $20-35 \%$, respectively, and the colectomy rates ranged from $14 \%$ to $53 \%$ in UC patients for complications or poor disease control. ${ }^{55}$

Studies assessing SD in IBD patients who underwent surgery are mainly related to restorative proctocolectomy (RP) with ileal pouch-anal anastomosis (IPAA) in UC. These studies are mainly retrospective, and their results have been controversial and hardly comparable due to the inclusion of different surgical techniques (open, laparoscopic, and robotic surgery), type of closure (manual or stapler closure), type of surgery (abdominal or pelvic) or type of reservoir (continent ileostomy or IPAA) ${ }^{56}$ Theoretically, rectal dissection could affect the innervation of the genital organs due to damage to the sympathetic and parasympathetic fibers, in addition to altering the pelvic anatomy, ${ }^{57}$ causing alterations in sexual functioning such as ejaculation disorders and ED in men, and dyspareunia, decreased vaginal lubrication, and pelvic pain in women. ${ }^{22}$ Despite these considerations, no differences in sexual function were found in patients with rectal cancer who underwent rectal resection by open surgery compared to laparoscopic surgery, ${ }^{58}$ and between complete proctectomy with laparoscopic IPAA formation and robotic or minimally invasive surgery in IBD patients. ${ }^{38}$ However, impaired body image, sex, age, psychiatric comorbidity, and pouch function may also be implicated in post-surgical SD. ${ }^{56}$

SD rates post-RP with IPAA in men range from 0 to $26 \%,{ }^{59}$ and concern mainly ejaculatory and ED. In this sense, Friedman et al demonstrated a higher risk of receiving an ED prescription in men with UC who have had UC surgery. ${ }^{31}$ A prospective study that included 762 men with UC who required IPAA reported a prevalence of retrograde ejaculation and anejaculation of $3 \%$ at 10 -year follow-up. ${ }^{60}$ A Japanese study reported a decreased sexual activity in 19 of 61 patients who underwent RP with IPAA, found that an IPAA after 40 years (Odds ratio 22) and total 
preoperative corticosteroid doses of $>15 \mathrm{~g}$ (Odds ratio 7.4) were predictors of deterioration of sexual activity. ${ }^{61}$ Other studies have confirmed that SD post RP with IPAA is associated with older age ${ }^{62,63}$ and that the use of sildenafil could reverse or completely improve post-RP ED in $79 \%$ of patients compared to $17 \%$ in the placebo group. ${ }^{64}$

A study of 83 women, with an average age of 38.4 years undergoing RP with IPAA due to UC, found that $47 \%$ had SD defined by an FSFI score $\leq 26$; however, the pouch function did not predict SD in this group of patients. ${ }^{19}$ Subsequently, Bengtsson et al, in a population of UC patients with IPAA, using FSFI and IIEF, did not find a higher SD in both women and men with pouch dysfunction compared to controls with UC with functioning pouch; however, those with pouch dysfunction showed a greater deterioration of body image ( $p<0.05$ in men and women). ${ }^{52}$ Similarly, other studies have shown that the prevalence of SD in men remained unchanged or even improved after undergoing RP with IPAA ${ }^{21,65}$ or complete proctectomy ${ }^{21}$ as well as the QoL of these patients. ${ }^{21,65,66}$

Different results have been reported in studies that included a wide variety of IBD-related surgeries. One series comparing IBD patients with a history of different types of surgery (limited bowel resections, colectomy/ ostomies, perianal surgeries, and pouch surgery) with nonoperated IBD subjects, showed high rates of decreased libido and impaired body image. However, in men, no differences were found between those who underwent surgery and those who did not, unlike in women who had a significantly greater negative impact, especially in those who underwent surgery. ${ }^{35}$ In this study and other studies, ${ }^{30}$ patients with ostomies had a worse body image than patients with other IBD-related surgeries. Patients with ostomies felt less attractive and desirable, had difficulty managing their ostomy during sexual intercourse, feared perception of odors from the ostomy, and suffered from deterioration of intimacy, low energy level, and loss of sexual drive. ${ }^{67}$

A study that included 88 patients with $\mathrm{CD}$ and a history of recent perianal surgery showed that QoL, but not sexual function, was influenced by surgery for perianal fistula. ${ }^{20}$

In summary, a greater post-surgical SD related to IBD has not been demonstrated; however, patients should be instructed on the potential risks of surgery and supported and supervised in this phase of the disease. Factors such as advanced age, the presence of a terminal ileostomy, and pouch failure could play a role in post-surgical SD. Women have shown a negative impact after surgery, mainly due to impaired body image and libido. ED after IPAA appears to be low and potentially treatable with currently available drugs.

\section{Sexual Dysfunction and Drugs Used in the Treatment of IBD}

IBD patients perceive a negative impact of the drugs used in the control of their disease on sexual activity. In a study of 217 IBD patients, Muller et al reported that $40 \%$ of patients felt that their medications negatively affected their libido or sexual activity, and about $10 \%$ of patients, sometimes or frequently omitted drugs for this reason. ${ }^{35}$

Adverse effects secondary to prolonged use of systemic corticosteroids (ie, acne, fluid retention, centripetal obesity, stretch marks, and hirsutism), regularly indicated in the management of IBD flares, can have a negative effect on body image, induce depression and undoubtedly influence the sexual function of these patients. ${ }^{68}$ In a study of IBD and SD in 336 women, corticosteroids were associated with low scores from the Brief Index of Sexual Functioning for Women (BISF-W) survey in the pleasure and orgasm domains with an Odds ratio of 2.4. ${ }^{36}$ Additionally, in a case-control study (355 IBD patients and 200 controls), Marín et al found that the use of corticosteroids in women (Odds ratio $0.42, p=0.005)$ and biological therapy in men (Odds ratio $0.17, \mathrm{p}=0.006$ ) were independent predictors of SD in IBD. ${ }^{13}$ Shmidt et al found a similar association between SD in women with newly diagnosed IBD and the use of biological therapy in multivariate analysis. However, in relation to this last point, other studies have not confirmed a deleterious effect of biological therapy on the sexual functioning of IBD patients. ${ }^{69,70}$ In general, biological therapy is an indirect marker of IBD severity, which could fundamentally explain the SD in these patients.

There are case reports of ED with methotrexate use in patients with rheumatoid arthritis that resolved after discontinuation of the medication; however, this has not been confirmed in IBD patients. ${ }^{71,72}$ For sulfasalazine, there is only one reported case of ED in a patient with UC. ${ }^{73}$ Other drugs frequently used in IBD, unrelated to direct treatment of the disease, can cause SD, which should be considered in the evaluation of these patients. Serotonin selective reuptake inhibitors (SSRI) have been associated with ED in $25-85 \%$ of patients, ${ }^{74}$ and the use of opioids can increase the risk of premature ejaculation by up to three times. $^{75}$ 


\section{Hypogonadism}

Hypogonadism may be present in IBD patients; it has been attributed to chronic inflammation and the use of some drugs. ${ }^{39}$ A study reported that over $40 \%$ of men with IBD suffer from hypogonadism with low testosterone levels. ${ }^{76}$ However, another recent study showed no difference in free testosterone levels between men with IBD and control subjects. ${ }^{77}$ It is known that hypogonadism is associated with SD; thus, it is recommended to evaluate the presence of this condition in IBD patients who report alterations in sexual functioning. ${ }^{39}$

\section{Sexual Dysfunction and Family Planning in IBD}

The influence of SD on the family planning of patients with IBD is unknown. Although fertility negatively affects a subgroup of women with IBD (CD patients, surgical procedures, active bowel inflammation), ${ }^{78}$ there is $17 \%$ of voluntary childlessness compared to $6 \%$ in the general population. ${ }^{79}$ Lack of knowledge and misperceptions about fertility and pregnancy in women with IBD is the main cause of voluntary childlessness, ${ }^{80,81}$ and lack of medical advice, among others. ${ }^{81}$ Fear of infertility, the side effect of medications, risk of congenital malformations and transmitting the disease to their offspring ${ }^{82}$ are reported by patients; however, other factors such as decreased libido, dyspareunia, chronic abdominal pain, and anxiety/depression disorders could also play a role. ${ }^{53}$ In men, SD is one of the etiologies of male infertility, due to ED and ejaculatory dysfunction, ${ }^{59}$ however, psychological factors could be involved in voluntary childlessness in this group. ${ }^{83}$

\section{A Practical Approach}

Currently, there are no recommendations or clinical guidelines for the treatment of SD in patients with IBD. Although the impact of IBD on sexual function is a frequent concern in patients, ${ }^{6}$ providers rarely consider this issue when discussing therapeutic goals with patients. In a study by Marin et al, $64 \%$ of women and almost half of the men surveyed wanted to receive information about the impact that IBD would have on their intimacy and sexuality at the time of diagnosis, mainly from an IBD specialist. ${ }^{13}$ The first step is that the medical team become aware of the importance of sexuality in the QoL of patients, deepen their knowledge about SD in IBD as well as fertility, and conduct an interview in an empathetic and assertive way, using open questions and active listening in order to investigate aspects of the patient's sexual health. Follow-up through validated questionnaires for SD, QoL, and anxiety and depression could screen highrisk patients for prompt management with a multidisciplinary team during the different phases of the disease (Figure 2). Control of disease activity guided by the gastroenterologist is essential to improve SD in patients with IBD. Although data on the influence of drugs used in IBD on sexual function are scarce, ${ }^{71-73}$ in patients with ED, methotrexate could be replaced by another immunosuppressant, as well as sulfasalazine by mesalazine. Sexologists or urologists or gynecologists with specialization in SD can direct the specific medical treatment according to the needs of the patient. In postsurgery ED in IBD, the use of sildenafil has shown encouraging results. ${ }^{64}$ There are no studies evaluating the use of testosterone replacement therapy in men with IBD with SD and hypogonadism, so its indication must be individualized. In the case of women, control and follow-up by the gynecologist could optimize the management of dyspareunia and local problems that may be influencing SD in this population. Comprehensive management of psychiatric disorders in patients with IBD and SD is essential. Pharmacological treatment guided by a psychiatrist avoiding antidepressants that potentially impair sexual functioning, for example SSRI, ${ }^{74}$ in addition to psychological therapy, is essential to improve the quality of life of patients. ${ }^{54}$

\section{Conclusions}

$\mathrm{SD}$ is a common and little-known problem in patients with IBD. Control of IBD activity does not appear to be sufficient to improve patients' QoL. Other aspects than the control of disease activity, such as mental and sexual health are relevant to the overall well-being of individuals with IBD. Similar to other chronic diseases, SD in IBD patients is higher than in the general population and may be present even before the IBD diagnosis and worsen with the course of the disease. SD in IBD is multifactorial, involving biological and psychosocial factors, and diseasespecific factors, such as the duration and activity of the disease, drug use, and surgery. An early investigation of SD in IBD patients through open questions and validated scales will allow a multidisciplinary approach, with the aim of improving the QoL of our patients. Further prospective studies evaluating SD in patients with IBD, as well as studies investigating interventions to improve SD in this population are needed. 


\section{Screening and Multidisciplinary Management of Sexual Dysfunction in IBD}

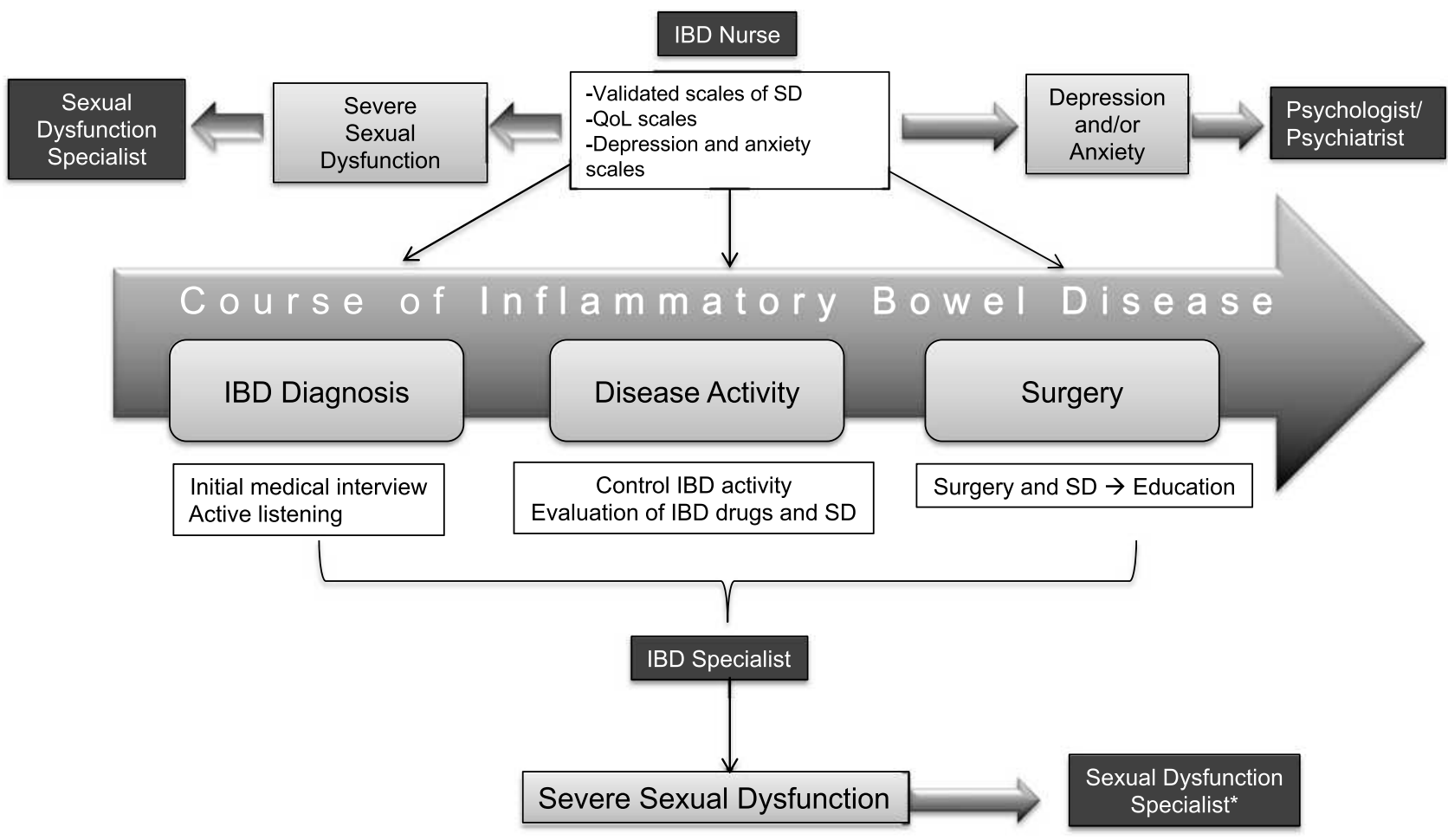

Figure 2 Screening and multidisciplinary management of sexual dysfunction in IBD. *Sexologist, urologist or gynecologist specializing in SD. Abbreviations: SD, sexual dysfunction; IBD, inflammatory bowel disease; QoL, quality of life.

\section{Abbreviations}

ASEX, Arizona Sexual Experiences Scale; BISF-W, Brief Index of Sexual Functioning for Women; CAI, Colitis Activity Index; CD, Crohn's disease; CDAI, Crohn's Disease Activity Index; ED, erectile dysfunction; FSDS, Female Sexual Distress Scale; FSFI, Female Sexual Function Index; HADS, Hospital Anxiety and Depression Scale; HBI, Harvey-Bradshaw Index; IBD, inflammatory bowel disease; IBD-FSDS, IBD-specific Female Sexual Dysfunction Scale; IBD-MSDS, IBD-Male Sexual Dysfunction Scale; IBS, irritable bowel syndrome; IIEF, International Index of Erectile Function; IPAA, ileal pouchanal anastomosis; QoL, quality of life; RR, relative risk; RR, restorative proctocolectomy; $\mathrm{SD}$, sexual dysfunction; SSRI, serotonin selective reuptake inhibitors; UC, ulcerative colitis.

\section{Funding}

This research did not receive any specific grant from funding agencies in the public, commercial, or not-for-profit sectors.

\section{Disclosure}

The authors report no conflicts of interest in this work.

\section{References}

1. Kuhnen A. Genetic and environmental considerations for inflammatory bowel disease. Surg Clin North Am. 2019;99(6):1197-1207. doi:10.1016/j.suc.2019.08.014.

2. Khor B, Gardet A, Xavier RJ. Genetics and pathogenesis of inflammatory bowel disease. Nature. 2011;474(7351):307-317. doi:10.1038/ nature10209.

3. Shapiro JM, Zoega H, Shah SA, et al. Incidence of Crohn's disease and ulcerative colitis in rhode island: report from the ocean state Crohn's and colitis area registry. Inflamm Bowel Dis. 2016;22 (6):1456-1461. doi:10.1097/MIB.0000000000000745.

4. Knowles SR, Keefer L, Wilding H, Hewitt C, Graff LA, MikockaWalus A. Quality of life in inflammatory bowel disease: a systematic review and meta-analyses-part II. Inflamm Bowel Dis. 2018;24 (5):966-976. doi:10.1093/ibd/izy015.

5. Drossman DA, Leserman J, Li ZM, Mitchell CM, Zagami EA, Patrick DL. The rating form of IBD patient concerns: a new measure of health status. Psychosom Med. 1991;53(6):701-712. doi:10.1097/ 00006842-199111000-00010.

6. Maunder R, Toner B, de Rooy E, Moskovitz D. Influence of sex and disease on illness- related concerns in inflammatory bowel disease. Can J Gastroenterol. 1999;13(9):728-732. doi:10.1155/1999/701645.

7. World Health Organization. Defining Sexual Health: Report of a Technical Consultation on Sexual Health, Geneva: 28-31 January 2002. WHO. 2006.

8. McCabe MP, Sharlip ID, Atalla E, et al. Definitions of sexual dysfunctions in women and men: a consensus statement from the fourth international consultation on sexual medicine 2015. J Sex Med. 2016;13(2):135-143. doi:10.1016/j.jsxm.2015.12.019. 
9. Clayton AH, Valladares Juarez EM. Female sexual dysfunction. Med Clin North Am. 2019;103(4):681-698. doi:10.1016/j.mcna.201 9.02.008

10. Gazzard BG, Price HL, Libby GW, Dawson AM. The social toll of Crohn's disease. $\mathrm{Br}$ Med J. 1978;2(6145):1117-1119. doi:10.1136/ bmj.2.6145.1117.

11. Moody G, Probert CSJ, Srivastava EM, Rhodes J, Mayberry JF. Sexual dysfunction amongst women with Crohn's disease: a hidden problem. Digestion. 1992;52(3-4):179-183. doi:10.1159/000200951.

12. Rivière P, Zallot C, Desobry P, et al. Frequency of and factors associated with sexual dysfunction in patients with inflammatory bowel disease. J Crohns Colitis. 2017;11(11):1347-1352. doi:10.10 93/ecco-jcc/jjx100.

13. Marín L, Mañosa M, Garcia-Planella E, et al. Sexual function and patients' perceptions in inflammatory bowel disease: a case-control survey. $J$ Gastroenterol. 2013;48(6):713-720. doi:10.1007/s00535012-0700-2.

14. Bel LG, Vollebregt AM, Van der Meulen-de Jong AE, et al. Sexual dysfunctions in men and women with inflammatory bowel disease: the influence of IBD-related clinical factors and depression on sexual function. $J$ Sex Med. 2015;12(7):1557-1567. doi:10.1111/jsm.12913.

15. Zhao S, Wang J, Liu Y, et al. Inflammatory bowel diseases were associated with risk of sexual dysfunction in both sexes: a meta-analysis. Inflamm Bowel Dis. 2019;25(4):699-707. doi:10.10 93/ibd/izy345.

16. Szydlarska D, Jakubowska A, Rydzewska G. Assessment of sexual dysfunction in patients with inflammatory bowel disease. Prz Gastroenterol. 2019;14(2):104-108. doi:10.5114/pg.2019.85893.

17. Rosen R, Brown C, Heiman J, et al. The female sexual function index (FSFI): a multidimensional self-report instrument for the assessment of female sexual function. $J$ Sex Marital Ther. 2000;26(2):191-208. doi:10.1080/009262300278597.

18. Rosen RC, Riley A, Wagner G, Osterloh IH, Kirkpatrick J, Mishra A. The international index of erectile function (IIEF): a multidimensional scale for assessment of erectile dysfunction. Urology. 1997;49(6):822-830. doi:10.1016/s0090-4295(97)00238-0.

19. Ogilvie JW Jr, Goetz L, Baxter NN, Park J, Minami S, Madoff RD. Female sexual dysfunction after ileal pouch-anal anastomosis. $\mathrm{Br}$ J Surg. 2008;95(7):887-892. doi:10.1002/bjs.6072.

20. Riss S, Schwameis K, Mittlböck M, et al. Sexual function and quality of life after surgical treatment for anal fistulas in Crohn's disease. Tech Coloproctol. 2013;17(1):89-94. doi:10.1007/s10151-012-0890-x.

21. Wang JY, Hart SL, Wilkowski KS, et al. Gender-specific differences in pelvic organ function after proctectomy for inflammatory bowel disease. Dis Colon Rectum. 2011;54(1):66-76. doi:10.1007/ DCR.0b013e3181fd48d2.

22. Cornish J, Wooding K, Tan E, Nicholls RJ, Clark SK, Tekkis PP. Study of sexual, urinary, and fecal function in females following restorative proctocolectomy. Inflamm Bowel Dis. 2012;18 (9):1601-1607. doi:10.1002/ibd.21910.

23. Wiegel M, Meston C, Rosen R. The female sexual function index (FSFI): cross-validation and development of clinical cutoff scores. $J$ Sex Marital Ther. 2005;31:1-20. doi:10.1080/00926230590475206.

24. Rosen RC, Cappelleri JC, Smith MD, Lipsky J, Peña BM. Development and evaluation of an abridged, 5-item version of the International Index of Erectile Function (IIEF-5) as a diagnostic tool for erectile dysfunction. Int J Impot Res. 1999;11(6):319-326. doi:10.1038/sj.ijir.3900472.

25. Weinfurt KP, Lin L, Bruner DW, et al. Development and initial validation of the PROMIS $\left({ }^{\circledR}\right)$ sexual function and satisfaction measures version 2.0. J Sex Med. 2015;12(9):1961-1974. doi:10.1111/ jsm. 12966

26. Gaidos JK, Naik K, Dave J, et al. High prevalence of male sexual dysfunction in a prospective multicenter VA inflammatory bowel disease population. Crohns Colitis. 2020;360(1):otaa004. doi:10.1093/crocol/ otaa004
27. Eluri S, Cross RK, Martin C, et al. Inflammatory bowel diseases can adversely impact domains of sexual function such as satisfaction with sex life. Dig Dis Sci. 2018;63(6):1572-1582. doi:10.1007/s10620018-5021-8.

28. Hatzichristou D, Kirana PS, Banner L, et al. Diagnosing sexual dysfunction in men and women: sexual history taking and the role of symptom scales and questionnaires. J Sex Med. 2016;13 (8):1166-1182. doi:10.1016/j.jsxm.2016.05.017.

29. O'Toole A, de Silva PS, Marc LG, et al. Sexual dysfunction in men with inflammatory bowel disease: a new IBD-specific scale. Inflamm Bowel Dis. 2018;24(2):310-316. doi:10.1093/ibd/izx053.

30. de Silva PS, O'Toole A, Marc LG, et al. Development of a sexual dysfunction scale for women with inflammatory bowel disease. Inflamm Bowel Dis. 2018;24(11):2350-2359. doi:10.1093/ibd/izy202.

31. Friedman S, Magnussen B, O'Toole A, Fedder J, Larsen MD, Nørgård BM. Increased use of medications for erectile dysfunction in men with ulcerative colitis and crohn's disease compared to men without inflammatory bowel disease: a Nationwide Cohort Study. $\mathrm{Am}$ J Gastroenterol. 2018;113(9):1355. doi:10.1038/s41395-018-0177-6

32. Shmidt E, Suárez-Fariñas M, Mallette $M$, et al. Erectile dysfunction is highly prevalent in men with newly diagnosed inflammatory bowel disease. Inflamm Bowel Dis. 2019;25(8):1408-1416. doi:10.1093/ibd/ izy401.

33. Timmer A, Bauer A, Kemptner D, Furst A, Rogler G. Determinants of male sexual function in inflammatory bowel disease: a surveybased cross-sectional analysis in $280 \mathrm{men}$. Inflamm Bowel Dis. 2007;13(10):1236-1243. doi:10.1002/ibd.20182.

34. Shmidt E, Suárez-Fariñas M, Mallette $\mathrm{M}$, et al. A longitudinal study of sexual function in women with newly diagnosed inflammatory bowel disease. Inflamm Bowel Dis. 2019;25:1262-1270. doi:10.1093/ibd/ izy397.

35. Muller KR, Prosser R, Bampton P, Mountifield R, Andrews JM. Female gender and surgery impair relationships, body image, and sexuality in inflammatory bowel disease: patient perceptions. Inflamm Bowel Dis. 2010;16(4):657-663. doi:10.1002/ibd.21090.

36. Timmer A, Kemptner D, Bauer A, Takses A, Ott C, Fürst A. Determinants of female sexual function in inflammatory bowel disease: a survey based cross-sectional analysis. BMC Gastroenterol. 2008;8(1):45. doi:10.1186/1471-230X-8-45.

37. Nohr EA, Nielsen J, Nørgård BM, Friedman S. Sexual health in women with inflammatory bowel disease in the Danish national birth cohort. J Crohns Colitis. 2020;14(8):1082-1089. doi:10.1093/ecco-jcc/jjaa038.

38. Miller AT, Berian JR, Rubin M, Hurst RD, Ficher A, Umanskiy K. Robotic-assisted proctectomy for inflammatory bowel disease: a case-matched com of laparoscopic and robotic technique. $J$ Gastrointest Surg. 2012;16(3):587-594. doi:10.1007/s11605-011-1692-6.

39. Ghazi LJ, Patil SA, Cross RK. Sexual dysfunction in inflammatory bowel disease. Inflamm Bowel Dis. 2015;21(4):939-947. doi:10.1097/MIB.0000000000000260.

40. Saha S, Zhao YQ, Shah SA, et al. Body image dissatisfaction in patients with inflammatory bowel disease. Inflamm Bowel Dis. 2015;21(2):345-352. doi:10.1097/MIB.0000000000000270.

41. Baars JE, Nuij VJ, Oldenburg B, Kuipers EJ, van der Woude CJ. Majority of patients with inflammatory bowel disease in clinical remission have mucosal inflammation. Inflamm Bowel Dis. 2012;18 (9):1634-1640. doi:10.1002/ibd.21925.

42. Fass R, Fullerton S, Naliboff B, Hirsh T, Mayer EA. Sexual dysfunction in patients with irritable bowel syndrome and nonulcer dyspepsia. Digestion. 1998;59(1):79-85. doi:10.1159/000007471

43. Sørensen J, Schantz Laursen B, Drewes AM, Krarup AL. The incidence of sexual dysfunction in patients with irritable bowel syndrome. Sex Med. 2019;7(4):371-383. doi:10.1159/000007471.

44. Perera LP, Radigan M, Guilday C, et al. Presence of irritable bowel syndrome symptoms in quiescent inflammatory bowel disease is associated with high rate of anxiety and depression. Dig Dis Sci. 2019;64(7):1923-1928. doi:10.1007/s10620-019-05488-8 
45. Pérez de Arce E, Sedano R, Quera R. Biomarcadores en enfermedad inflamatoria intestinal: ¿sabe cómo utilizarlos? Rev Méd Chile. 2020;148(3):362-370. doi:10.4067/S0034-98872020000300362

46. Grimstad T, Norheim KB, Isaksen K, et al. Fatigue in newly diagnosed inflammatory bowel disease. J Crohns Colitis. 2015;9 (9):725-730. doi:10.1093/ecco-jcc/jjv091.

47. Nocerino A, Nguyen A, Agrawal M, Mone A, Lakhani K, Swaminath A. Fatigue in inflammatory bowel diseases: etiologies and management. Adv Ther. 2020;37(1):97-112. doi:10.1007/ s12325-019-01151-w.

48. Romberg-Camps MJ, Bol Y, Dagnelie PC. Fatigue and health-related quality of life in inflammatory bowel disease: results from a population-based study in the Netherlands: the IBD-South Limburg cohort. Inflamm Bowel Dis. 2010;16(12):2137-2147. doi:10.1002/ ibd. 21285 .

49. Lakhani KAM, Bhardwaj R, Swaminath A. Fatigue is inversely associated with endoscopic but not histologic remission in IBD patients. ACG Annual Scientific Meeting and Postgraduate Course. PO511; October 27; 2019.

50. Clayton AH, El Haddad S, Iluonakhamhe JP, Ponce Martinez C, Schuck AE. Sexual dysfunction associated with major depressive disorder and antidepressant treatment. Expert Opin Drug Saf. 2014t;13(10):1361-1374. doi:10.1517/14740338.2014.951324.

51. Mikocka-Walus A, Knowles SR, Keefer L, Graff L. Controversies revisited: a systematic review of the comorbidity of depression and anxiety with inflammatory bowel diseases. Inflamm Bowel Dis. 2016;22(3):752-762. doi:10.1097/MIB.0000000000000620.

52. Bengtsson J, Lindholm E, Nordgren S, Berndtsson I, Oresland T, Börjesson L. Sexual function after failed ileal pouch-anal anastomosis. J Crohns Colitis. 2011;5(5):407-414. doi:10.1016/j. crohns.2011.04.002.

53. Timmer A, Bauer A, Dignass A, Rogler G. Sexual function in persons with inflammatory bowel disease: a survey with matched controls. Clin Gastroenterol Hepatol. 2007;5(1):87-94. doi:10.1016/ j.cgh.2006.10.018.

54. Yanartas O, Kani HT, Bicakci E, et al. The effects of psychiatric treatment on depression, anxiety, quality of life, and sexual dysfunction in patients with inflammatory bowel disease. Neuropsychiatr Dis Treat. 2016;12:673-683. doi:10.2147/NDT.S106039.

55. Wong DJ, Roth EM, Feuerstein JD, Poylin VY. Surgery in the age of biologics. Gastroenterol Rep (Oxf). 2019;7(2):77-90. doi:10.1093/ gastro/goz004.

56. Hammami MB, Mahadevan U. Men with inflammatory bowel disease: sexual function, fertility, medication safety, and prostate cancer. Am J Gastroenterol. 2020;115(4):526-534. doi:10.14309/ajg.00000 00000000515.

57. Slors FJ, van Zuijlen PP, van Dijk GJ. Sexual and bladder dysfunction after total mesorectal excision for benign diseases. Scand J Gastroenterol Suppl. 2000;232:48-51. PMID: 11232492.

58. Lim RS, Yang TX, Chua TC. Postoperative bladder and sexual function in patients undergoing surgery for rectal cancer: a systematic review an meta-analysis of laparoscopic versus open resection of rectal cancer. Tech Coloproctol. 2014;18(11):993-1002. doi:10.1007/s10151-014-1189-x

59. Allocca M, Gilardi D, Fiorino G, Furfaro F, Peyrin-Biroulet L, Danese S. Sexual and reproductive issues and inflammatory bowel disease: a neglected topic in men. Eur J Gastroenterol Hepatol. 2018;30(3):316-322. doi:10.1097/MEG.0000000000001074.

60. Farouk R, Pemberton JH, Wolff BG, Dozois RR, Browning S, Larson D. Functional outcomes after ileal pouch-anal anastomosis for chronic ulcerative colitis. Ann Surg. 2000;231(6):919-926. doi:10.1097/00000658-200006000-00017.

61. Yoshida K, Araki T, Uchida K, et al. Sexual activity after ileal pouch anal anastomosis in Japanese patients with ulcerative colitis. Surg Today. 2014;44(1):73-79. doi:10.1007/s00595-013-0505-9.
62. Lindsey I, George BD, Kettlewell MG, Mortensen NJ. Impotence after mesorectal and close rectal dissection for inflammatory bowel disease. Dis Colon Rectum. 2001;44(6):831-835. doi:10.1007/ BF02234703.

63. Van Balkom KA, Beld MP, Visschers RG, van Gemert WG, Breukink SO. Long-term results after restorative proctocolectomy with ileal pouch-anal anastomosis at a young age. Dis Colon Rectum. 2012;55(9):939-947. doi:10.1097/DCR.0b013e31825bd7f4.

64. Lindsey I, George B, Kettlewell M, Mortensen N. Randomized, double-blind, placebo-controlled trial of sildenafil (Viagra) for erectile dysfunction after rectal excision for cancer and inflammatory bowel disease. Dis Colon Rectum. 2002;45(6):727-732. doi:10.1007/s10350-004-6287-9.

65. Gorgun E, Remzi FH, Montague DK, et al. Male sexual function improves after ileal pouch anal anastomosis. Colorectal Dis. 2005;7 (6):545-550. doi:10.1111/j.1463-1318.2005.00895.x.

66. Cohan JN, Rhee JY, Finlayson E, Varma MG. Impact of surgery on relationship quality in patients with ulcerative colitis and their partners. Dis Colon Rectum. 2015;58(12):1144-1150. doi:10.1097/ DCR.0000000000000494.

67. Carlsson E, Bosaeus I, Nordgren S. What concerns subjects with inflammatory bowel disease and an ileostomy? Scand J Gastroenterol. 2003;38 (9):978-984. doi:10.1080/00365520310004687.

68. Mitchell A, O’Keane V. Steroids and depression. BMJ. 1998;316 (7127):244-245. doi:10.1136/bmj.316.7127.244.

69. Kanar O, Berry AC, Nakshabendi R, et al. Effects of immunomodulators and biologic agents on sexual health in patients with inflammatory bowel disease. Ochsner J. 2017;17(2):150-156. PMID: 28638288.

70. Semet M, Paci M, Saïas-Magnan J, et al. The impact of drugs on male fertility: a review. Andrology. 2017;5(4):640-663. doi:10.1111/ andr. 12366 .

71. Blackburn WD Jr, Alarcon GS. Impotence in three rheumatoid arthritis patients treated with methotrexate. Arthritis Rheum. 1989;32 (10):1341-1342. doi:10.1002/anr.1780321029.

72. Thomas E, Koumouvi K, Blotman F. Impotence in a patient with rheumatoid arthritis treated with methotrexate. J Rheumatol. 2000;27 (7):1821-1822. PMID: 10914881.

73. Ireland A, Jewell DP. Sulfasalazine-induced impotence: a beneficial resolution with olsalazine? J Clin Gastroenterol. 1989;11(6):711. PMID: 2573629.

74. Serretti A, Chiesa A. Treatment-emergent sexual dysfunction related to antidepressants: a meta-analysis. J Clin Psychopharmacol. 2009;29(3):259-266. doi:10.1097/JCP.0b013e3181a5233f.

75. Chekuri V, Gerber D, Brodie A, Krishnadas R. Premature ejaculation and other sexual dysfunctions in opiate dependent men receiving methadone substitution treatment. Addict Behav. 2012;37 (1):124-126. doi:10.1016/j.addbeh.2011.08.005.

76. Szathmari M, Vásárhelyi B, Treszl A, Tulassay T, Tulassay Z. Association of dehydroepiandrosterone sulfate and testosterone deficiency with bone turnover in men with inflammatory bowel disease. Int J Colorectal Dis. 2002;17(2):63-66. doi:10.1007/s003840100334.

77. Valer P, Algaba A, Santos D, et al. Evaluation of the quality of semen and sexual function in men with inflammatory bowel disease. Inflamm Bowel Dis. 2017;23(7):1144-1153. doi:10.1097/ MIB.0000000000001081.

78. Druvefors E, Landerholm K, Hammar U, Myrelid P, Andersson RE. Impaired fertility in women with inflammatory bowel disease: a National Cohort Study from sweden. J Crohns Colitis. 2021;15 (3):383-390. doi:10.1093/ecco-jcc/jjaa191

79. Marri SR, Ahn C, Buchman AL. Voluntary childlessness is increased in women with inflammatory bowel disease. Inflamm Bowel Dis. 2007;13(5):591-599. doi:10.1002/ibd.20082

80. Ellul P, Zammita SC, Katsanos KH, et al. Perception of reproductive health in women with inflammatory bowel disease [published correction appears in J Crohns Colitis. 2019 May 27;13(6):815]. J Crohns Colitis. 2016;10(8):886-891. doi:10.1093/ecco-jcc/jjw011 
81. Selinger CP, Ghorayeb J, Madill A. What factors might drive voluntary childlessness (VC) in women with IBD? Does IBD-specific pregnancy-related knowledge matter? J Crohns Colitis. 2016;10 (10):1151-1158. doi:10.1093/ecco-jcc/jjw078

82. Mountifield R, Bampton P, Prosser R, Muller K, Andrews JM. Fear and fertility in inflammatory bowel disease: a mismatch of perception and reality affects family planning decisions. Inflamm Bowel Dis. 2009;15(5):720-725. doi:10.1002/ibd.20839
83. Andrews JM, Mountifield RE, Van Langenberg DR, Bampton PA, Holtmann GJ. Un-promoted issues in inflammatory bowel disease: opportunities to optimize care. Intern Med J. 2010;40(3):173-182. doi:10.1111/j.1445-5994.2009.02110.x

\section{Publish your work in this journal}

The International Journal of General Medicine is an international, peer-reviewed open-access journal that focuses on general and internal medicine, pathogenesis, epidemiology, diagnosis, monitoring and treatment protocols. The journal is characterized by the rapid reporting of reviews, original research and clinical studies across all disease areas. The manuscript management system is completely online and includes a very quick and fair peer-review system, which is all easy to use. Visit http://www.dovepress.com/ testimonials.php to read real quotes from published authors. 